\title{
Integrated additive design and manufacturing approach for the bioengineering of bone scaffolds for favorable mechanical and biological properties
}

Citation for published version (APA):

Valainis, D., Dondl, P., Foehr, P., Burgkart, R., Kalkhof, S., Duda, G. N., van Griensven, M., \& Poh, P. S. P. (2019). Integrated additive design and manufacturing approach for the bioengineering of bone scaffolds for favorable mechanical and biological properties. Biomedical Materials, 14(6), [065002]. https://doi.org/10.1088/1748-605X/ab38c6

Document status and date:

Published: 01/11/2019

DOI:

10.1088/1748-605X/ab38c6

Document Version:

Publisher's PDF, also known as Version of record

Document license:

Taverne

Please check the document version of this publication:

- A submitted manuscript is the version of the article upon submission and before peer-review. There can be important differences between the submitted version and the official published version of record.

People interested in the research are advised to contact the author for the final version of the publication, or visit the DOI to the publisher's website.

- The final author version and the galley proof are versions of the publication after peer review.

- The final published version features the final layout of the paper including the volume, issue and page numbers.

Link to publication

\footnotetext{
General rights rights.

- You may freely distribute the URL identifying the publication in the public portal. please follow below link for the End User Agreement:

www.umlib.nl/taverne-license

Take down policy

If you believe that this document breaches copyright please contact us at:

repository@maastrichtuniversity.nl

providing details and we will investigate your claim.
}

Copyright and moral rights for the publications made accessible in the public portal are retained by the authors and/or other copyright owners and it is a condition of accessing publications that users recognise and abide by the legal requirements associated with these

- Users may download and print one copy of any publication from the public portal for the purpose of private study or research.

- You may not further distribute the material or use it for any profit-making activity or commercial gain

If the publication is distributed under the terms of Article $25 \mathrm{fa}$ of the Dutch Copyright Act, indicated by the "Taverne" license above, 
PAPER

Integrated additive design and manufacturing approach for the bioengineering of bone scaffolds for favorable mechanical and biological properties

To cite this article: Dvina Valainis et al 2019 Biomed. Mater. 14065002

\section{Recent citations}

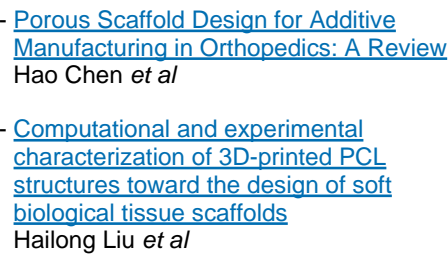

Porous Scaffold Desian for Additive Manufacturing in Orthopedics: A Review Computational and experimental characterization of 3D-printed PCL biological tissue scaffolds Hailong Liu et al

View the article online for updates and enhancements.

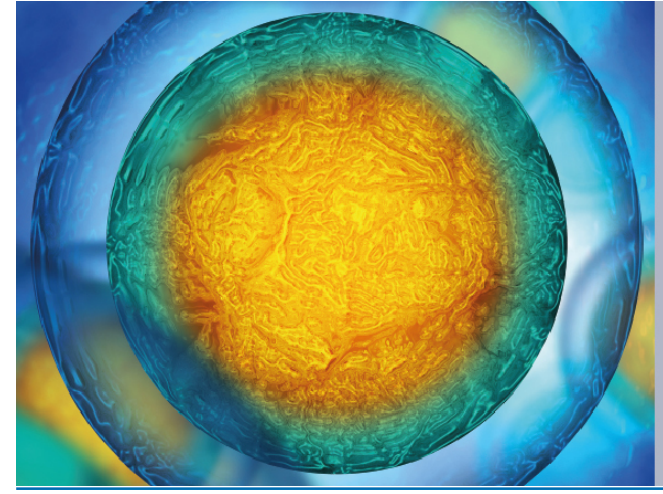

Biophysical Society $I O P \mid$ ebooks $^{\text {tw }}$

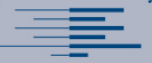

Your publishing choice in all areas of biophysics research.

Start exploring the collection-download the first chapter of every title for free. 


\title{
Biomedical Materials
}

\section{PAPER}

CrossMark

\section{Integrated additive design and manufacturing approach for the bioengineering of bone scaffolds for favorable mechanical and biological properties}

PEVISED

23 July 2019

ACCEPTED FOR PUBLICATION

6 August 2019

PUBLISHED

9 September 2019

\author{
Dvina Valainis ${ }^{1}$, Patrick Dondl ${ }^{2}$, Peter Foehr ${ }^{3}$, Rainer Burgkart ${ }^{3}$, Stefan Kalkhof ${ }^{4,5}$, Georg N Duda ${ }^{6}$, \\ Martijn van Griensven ${ }^{1}$ and Patrina S P Poh ${ }^{1,6}$ (B) \\ 1 Experimental Trauma Surgery, Technical University of Munich, Ismaninger Str. 22, D-81675 Munich, Germany \\ 2 Department of Applied Mathematics, Albert Ludwigs University of Freiburg, Hermann-Herder-Str. 10, D-79104 Freiburg i. Br., \\ Germany \\ 3 Clinic of Orthopaedics and Sports Orthopaedics, Biomechanics Laboratory, Technical University of Munich, Ismaninger Str. 22, \\ D-81675 Munich, Germany \\ 4 Institute of Bioanalysis, University of Applied Sciences and Arts of Coburg, Friedrich-Streib-Str. 2, D-96450 Coburg, Germany \\ 5 Fraunhofer Institute of Cell Therapy and Immunology, Department of Therapy Validation, Perlickstr. 1, D-04103 Leipzig, Germany \\ 6 Julius Wolff Institute, Charité - Universitätsmedizin Berlin, Augustenburger Platz 1, D-13353 Berlin, Germany \\ E-mail: patrina.poh@charite.de
}

Keywords: triply periodic minimal surfaces, cell migration, finite element simulation, biomechanical testing, adipose-derived mesenchymal stromal cells, polycaprolactone

Supplementary material for this article is available online

\begin{abstract}
Additive manufacturing (AM) presents the possibility of personalized bone scaffolds with unprecedented structural and functional designs. In contrast to earlier conventional design concepts, e.g. raster-angle, a workflow was established to produce scaffolds with triply periodic minimal surface (TPMS) architecture. A core challenge is the realization of such structures using melt-extrusion based $3 \mathrm{D}$ printing. This study presents methods for generation of scaffold design files, finite element (FE) analysis of scaffold Young's moduli, AM of scaffolds with polycaprolactone (PCL), and a customized in vitro assay to evaluate cell migration. The reliability of FE analysis when using computer-aided designed models as input may be impeded by anomalies introduced during 3D printing. Using microcomputed tomography reconstructions of printed scaffolds as an input for numerical simulation in comparison to experimentally obtained scaffold Young's moduli showed a moderate trend $\left(R^{2}=0.62\right)$. Interestingly, in a preliminary cell migration assay, adipose-derived mesenchymal stromal cells (AdMSC) migrated furthest on PCL scaffolds with Diamond, followed by Gyroid and Schwarz P architectures. A similar trend, but with an accelerated AdMSC migration rate, was observed for PCL scaffolds surface coated with calcium-phosphate-based apatite. We elaborate on the importance of start-to-finish integration of all steps of AM, i.e. design, engineering and manufacturing. Using such a workflow, specific biological and mechanical functionality, e.g. improved regeneration via enhanced cell migration and higher structural integrity, may be realized for scaffolds intended as temporary guiding structures for endogenous tissue regeneration.
\end{abstract}

\section{Introduction}

Additive manufacturing (AM), also known as 3D printing, is a layer-wise deposition of material to produce a 3D object, as opposed to, e.g. subtractive and formative manufacturing technologies. This rapidly emerging technology offers the potential to produce scaffolds capable of supporting tissue engineering and regenerative therapies with unprecedented structural and functional designs that could not otherwise be created.

Fifteen years since the introduction of AM into regenerative medicine, scaffold designs are still predominantly based on a 'raster-angle' design approach, where evenly spaced strands of material are laid down layer by layer, with rotations between the layers 
(e.g. $0 / 90^{\circ}, 0 / 60 / 120^{\circ}$ ) [1-4]. Scaffolds with rasterangle designs made of a variety of biomaterials have been extensively studied in vitro and in vivo, showing great potential in bone tissue regeneration [5, 6]. However, this design concept offers only a limited number of possible architectures (i.e. limited number of possible strut deposition angles) and, by virtue of the isolated contact points between layers, only limited mechanical strength. AM approaches often have to compromise the mechanical strength of the scaffolds in order to achieve favorable biological properties (e.g. porosity $>60 \%$ and pore interconnectivity for adequate mass transport and to provide sufficient surface area for cell-biomaterial interactions to promote osteoconduction [7]). Thus, alternatives to the rasterangle design approach may be preferable for scaffolds intended for bone regeneration $[8,9]$.

As AM technology progresses, so has the exploration of design principles that truly embrace the freedom-of-design capability of AM. The approach of designing scaffolds using more general mathematical models opens up endless possibilities in terms of scaffold microstructure. One of the most promising mathematical models for scaffold design is based on triplyperiodic minimal surfaces (TPMS) [9], which automatically satisfy the requirement for pore interconnectivity. One of the advantages of using TPMS microstructure for the design of scaffolds intended for bone regeneration is the potential for improved mechanical performance of scaffolds while retaining high porosity, which is crucial to enable cell infiltration and blood vessel in-growth, thus establishing an optimal microenvironment within the regeneration niche to ensure successful bone healing.

In this study, scaffolds with a variety of TPMS architectures were designed and fabricated using a melt-extrusion based 3D printer. All scaffolds were made from polycaprolactone (PCL), an aliphatic thermoplastic widely used in the manufacturing of scaffolds due to its good rheological and viscoelastic properties compared to other synthetic polymers [10]. Most notably, the adsorption rate of PCL when implanted in humans ( $>2$ years) and the relatively high elastic modulus compared to other thermoplastics (e.g. polylactide, polyglycolide) make PCL an especially attractive biomaterial for scaffolds intended for bone regeneration [10]. However, PCL is inherently hydrophobic; therefore, unfavorable for cell attachment [10]. To circumvent this, PCL scaffolds' surfaces can be modified with plasma treatment or sodium hydroxide etching and coated with calciumphosphate (CaP)-based apatite to improve surface hydrophilicity, providing favorable biological potential to the scaffold [11].

Surprisingly, most TPMS structures for tissue engineering and regenerative medicine (TERM) applications have only been investigated as computational models [9, 12-15] and only a handful of studies have successfully fabricated and characterized the physical properties (mostly mechanical properties) of scaffolds with TPMS architecture [8, 16, 17]. To date, most studies have employed computer-aided design (CAD) scaffolds for simulation without taking into account the anomalies that arise from the AM printing processes. Therefore, the first goal of this work is to establish whether CAD generated scaffolds can be used as a reliable input for numerical simulation of scaffolds' mechanical properties. To this end, we compared finite element (FE) compression simulation of CAD generated scaffolds of different TPMS architectures with that of $3 \mathrm{D}$ reconstructed models of printed scaffolds obtained through micro-computed tomography ( $\mu \mathrm{CT})$. Simulation outcomes were further validated with experimental mechanical tests.

Earlier work by our group has shown that highly aligned scaffolds may direct cellular migration, and in doing so, foster bone defect regeneration. Structuredependent bone ingrowth was seen in PCL scaffolds [18-20], titanium AM scaffolds [21], and freeze-dried scaffolds with aligned pores [22]. However, to date, it remains unknown if AM scaffolds could be optimized with TPMS architecture to support cellular migration to be even more conducive to tissue regeneration. The second goal of this study is thus to investigate the dependence of cells on scaffold geometries for migration along the scaffolds, with or without a CaP surface coating.

\section{Methods and materials}

\subsection{Scaffold design}

Three TPMS, namely Gyroid, Schwarz P, and Diamond $[9,23]$, were selected as test cases for this study (figure 1), based on their printability without additional sacrificial support material.

In order to produce input files for the AM process, the following method was employed. The TPMSbased volume, $\Omega$, which is to be printed, is approximated by an implicit triply-periodic function, $f$, defined on a unit cube, i.e. $\Omega=\{|f(x, y, z)| \leqslant \alpha\}$. The function, $f$, is chosen such that the set $\Sigma=\{f(x, y$, $z)=0\}$ is an approximation of a TPMS. See figure 1 for the surfaces generated, as well as the corresponding implicit functions $f$. It follows that $\Omega$ is given by a neighborhood of $\Sigma$ with a thickness of approximately $2 \alpha /|\nabla f|$. The parameter, $\alpha$, is chosen such that the volume fraction (i.e. the volume of $\Omega$ intersected with the unit cube, which corresponds to one minus the sample porosity) matches the desired value, e.g. $40 \%$. Using a custom MATLAB script, the implicit volume $\Omega$ was discretized and output as a smoothed threedimensional image in INRIA's .INR format (with grey scale values of 1 on the inside of $\Omega, 0$ on the outside and a thin transition layer between the two). This transition is then triangulated using the mesh generation function provided by CGAL [24], resulting in a triangulation description in .OFF (object file format), 


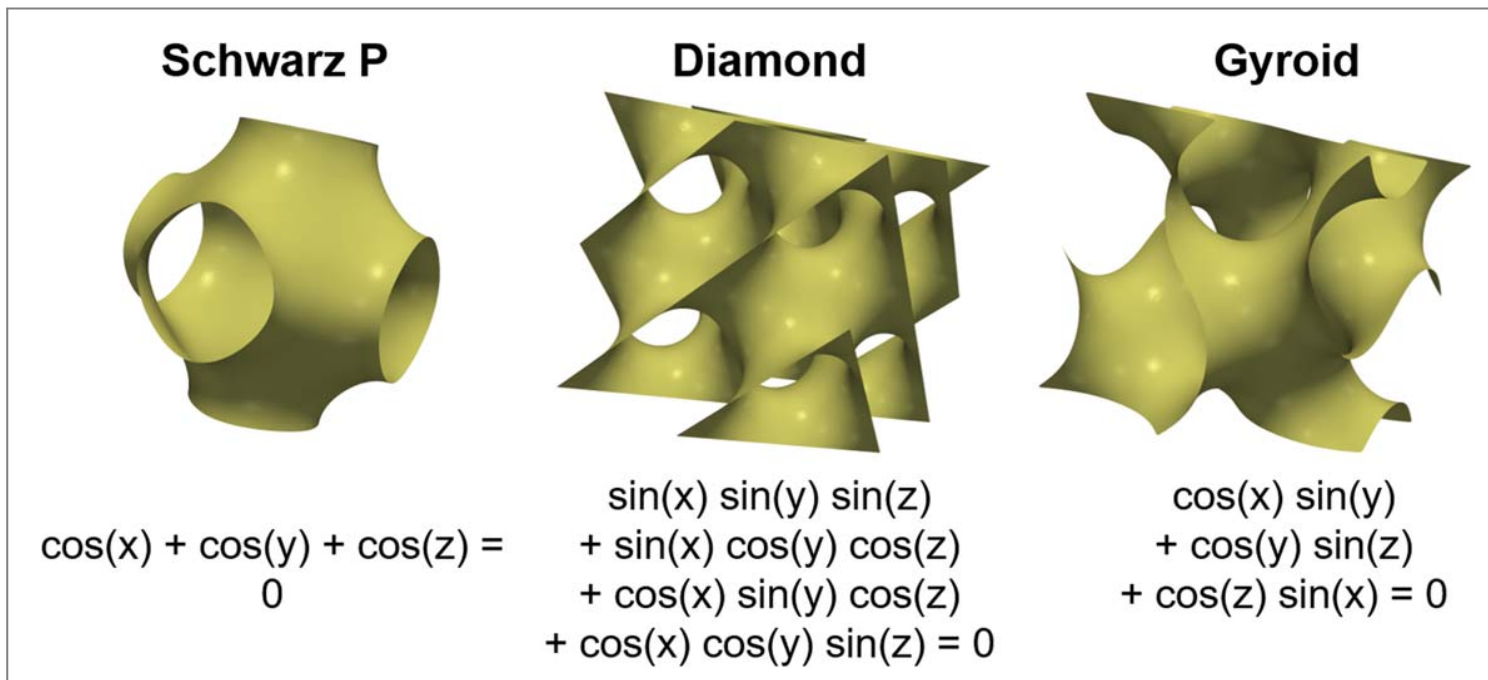

Figure 1. The unit cells of the three investigated TPMS scaffold designs, together with their approximations as implicit functions.

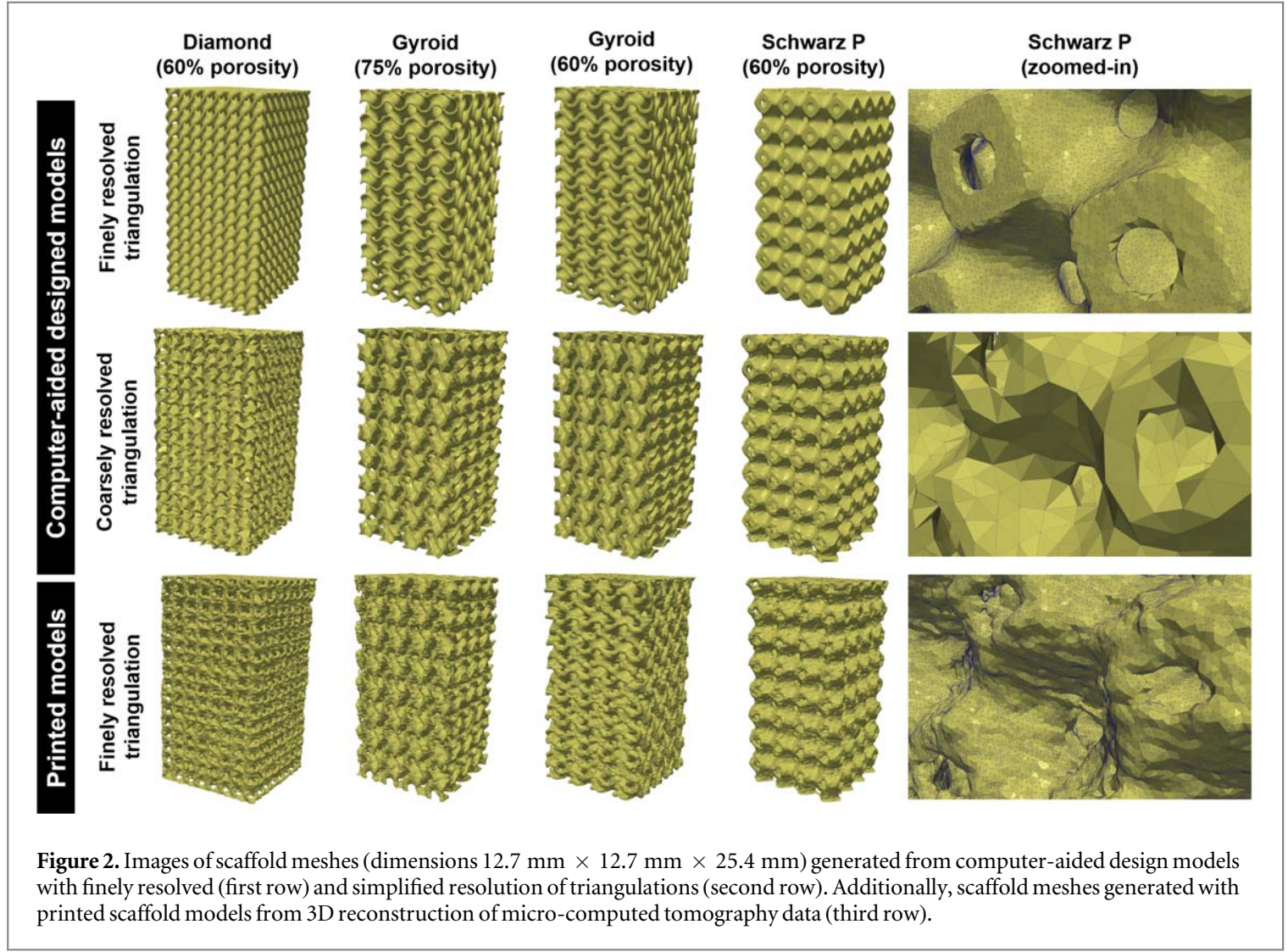

which can be further processed for FE analysis or manufacturing of scaffolds.

The initial objects in .OFF format had a polygon count of roughly $10^{6}$ faces. These meshes were simplified to achieve a reduced polygon count of approximately $6 \times 10^{4}$ faces using MeshLab's [25] Quadric Edge Collapse Decimation simplification routine. See figure 2 for the original and simplified designs with finely and coarsely resolved triangulation, respectively. The resulting object description as a polyhedral surface was saved in . STL (stereolithography) format for printing. In all cases, the objects to be compression tested were composed of
$4 \times 4 \times 8$ unit cells and scaled to total dimensions of $12.7 \mathrm{~mm} \times 12.7 \mathrm{~mm} \times 25.4 \mathrm{~mm}$, as suggested in the ASTM testing protocol [26]. Additionally, scaffolds of dimensions $3.175 \mathrm{~mm} \times 4.7625 \mathrm{~mm} \times 19.5 \mathrm{~mm}$ and the same unit cell sizes as for compression testing were manufactured for the cell migration assay.

For the mechanical testing, scaffolds of $60 \%$ nominal porosity in the Gyroid, Diamond, and Schwarz $\mathrm{P}$ geometries, as well as scaffolds of $75 \%$ nominal porosity in the Gyroid geometry were manufactured. For the migration assay, the same three geometries were printed, all with a nominal porosity of $60 \%$. 
Table 1. Parameters used for the manufacturing of the printed scaffolds.

\begin{tabular}{lcc}
\hline Parameter & Gyroid and Schwarz P & Diamond \\
\hline Printing pressure & $660 \mathrm{kPa}$ & $660 \mathrm{kPa}$ \\
Print temperature & $105{ }^{\circ} \mathrm{C}$ & $105{ }^{\circ} \mathrm{C}$ \\
Print speed & $2 \mathrm{~mm} \mathrm{~s}^{-1}$ & $2 \mathrm{~mm} \mathrm{~s}^{-1}$ \\
Layer height & $170 \mu \mathrm{m}$ & $170 \mu \mathrm{m}$ \\
Distance between strands & $0.13 \mathrm{~mm}$ & $0.15 \mathrm{~mm}$ \\
Turn between layers & $30^{\circ}$ & $30^{\circ}$ \\
Pause between layers & $9 \mathrm{~s}$ & $9 \mathrm{~s}$ \\
Start break & $-0.2 \mathrm{~s}$ & $-0.2 \mathrm{~s}$ \\
End break & $0.1 \mathrm{~s}$ & $0.1 \mathrm{~s}$ \\
\hline
\end{tabular}

\subsection{Scaffold fabrication}

Scaffolds in the different porosities and geometries were printed using $43 \mathrm{kDa}$ PCL (Polysciences) on a GeSiM BioScaffolder (Model 3.1). The print parameters as input to the proprietary GeSiM software are listed in table 1.

\subsection{Simulation of scaffold mechanical properties}

The starting point for the simulations was a polyhedral surface mesh, either obtained directly from the scaffold generation procedure outlined in section 2.1, or by triangulating a 3D-image obtained from the $\mu \mathrm{CT}$ data described in section 2.5 (using the aforementioned CGAL-routine). The volume enclosed by these polyhedral surfaces was tetrahedralized using the program TetGen (Version 1.5.0) [27], in order to produce a high-quality tetrahedralization (using approximately $8 \times 10^{6}$ tetrahedra for our given samples) of the given volume.

On this tetrahedralized volume a simple simulated compression test (under hard-loaded compressive boundary conditions on the top and bottom of the samples, free boundary conditions everywhere else) was performed such that the ratio of the effective Young's modulus and the material Young's modulus of the samples could be determined. The numerical simulation employed in our tests is a custom made P1 FE program developed in $\mathrm{C}++$. The material in the simulation was chosen to be an isotropic linearly elastic solid with a Poisson's ratio of 0.3 . We note that the ratio of the effective Young's modulus of the periodic structure and the Young's modulus of the material is simply given by the ratio of the elastic energy computed in the simulation and the elastic energy of a linearly elastic bulk material of the same dimensions with the given material Young's modulus under the same loading conditions. This bulk material elastic energy can easily be calculated using the formula $U_{\mathrm{el}}=1 / 2 E e^{2} V$, where $E$ is the material Young's modulus, $e$ is the engineering strain given by the compressive boundary conditions, and $V$ is the volume of the undeformed sample (in our case, $12.7 \mathrm{~mm} \times 12.7 \mathrm{~mm} \times 25.4 \mathrm{~mm}$ ). Due to the assumption of linear elasticity, the energy computed in the simulation is also quadratic in the engineering strain, the value of $e$ can be chosen arbitrarily and the computed Young's modulus ratio does not depend on the choice.

\subsection{Compression testing of scaffolds}

The scaffolds were characterized by compression testing on a uniaxial system (Zwicki 1120, Zwick/Roell, Ulm, Germany) with a load cell (KAF-Z 2.5 kN, A.S.T. GmbH, Dresden, Germany). The Young's moduli of blocks of the bulk material with the same dimensions as the printed scaffolds were measured for use in the simulations. The protocol for the compression testing was adapted from the ASTM standard for rigid plastics (ASTM D 695-15) [26] using printed scaffolds of nominal dimensions $12.7 \mathrm{~mm} \times 12.7 \mathrm{~mm} \times 25.4 \mathrm{~mm}$. No special fixation was used for the scaffolds. A preloading force of $0.2 \mathrm{~N}$ was applied to eliminate the 'toe zone'. A compression rate of $1 \mathrm{~mm} \mathrm{~min}^{-1}$ was applied until a compression level of $10 \%$ was reached. The scaffolds were then cycled between $10 \%$ and $5 \%$ engineering strain. After the third loading cycle, a steady state behavior was observed in the stress-strain diagram. The effective Young's modulus of the scaffolds was computed as the stress-strain slope of the fifth loading cycle.

\subsection{Micro-computed tomography characterization of scaffold properties}

Scaffolds were scanned using a Bruker $\mu \mathrm{CT}$ (Skyscan 1176 , Kontich, Belgium) at $40 \mathrm{kV}$ with $9 \mu \mathrm{m}$ resolution. Actual printed porosity and 'pore size' (as trabecular separation) were determined using the Bruker software CTAnalyser [28, 29]. Meshes generated from the scanned scaffolds were fed into the simulation described in section 2.3.

\subsection{Etching and calcium phosphate coating of scaffolds}

The scaffolds for the cell migration assay were etched to increase their hydrophilicity. Scaffolds were immersed in $70 \%$ ethanol for 30 min under vacuum, rinsed with distilled water $\left(\mathrm{dH}_{2} \mathrm{O}\right)$, and treated with pre-warmed $5.0 \mathrm{M}$ sodium hydroxide $(\mathrm{NaOH})$ for 10 min under vacuum, followed by immersion in $5.0 \mathrm{M} \mathrm{NaOH}$ for four hours at $37^{\circ} \mathrm{C}$. The scaffolds were then rinsed with $\mathrm{dH}_{2} \mathrm{O}$ until the rinse water reached $\mathrm{pH}$ 7. To compare cell migration with and without a $\mathrm{CaP}$ coating, half the scaffolds were surface coated with $\mathrm{CaP}$ as previously described in [30] and [11]. Following the etching step described above, scaffolds were covered with $10 \times$ simulated body fluid (SBF) of $\mathrm{pH} 6$ under vacuum for $5 \mathrm{~min}$, then immersed in $10 \times \mathrm{SBF}$ at $37^{\circ} \mathrm{C}$ for $60 \mathrm{~min}$ total, with one change of fresh $10 \times \mathrm{SBF}, \mathrm{pH} 6$, after $30 \mathrm{~min}$. Finally, the scaffolds were subjected to $5.0 \mathrm{M} \mathrm{NaOH}$ treatment for $30 \mathrm{~min}$ at $37^{\circ} \mathrm{C}$ then gently washed with $\mathrm{dH}_{2} \mathrm{O}$ until the wash solutions reached $\mathrm{pH} 7$. 


\subsection{Scaffold sterilization}

The scaffolds were first immersed in $70 \%$ ethanol for $30 \mathrm{~min}$. Excess $70 \%$ ethanol was gently aspirated and the scaffolds were allowed to air dry in a single layer under sterile conditions. Prior to cell seeding, scaffolds were treated with $20 \mathrm{~min}$ on each broad side with ultraviolet (UV) light.

\subsection{Polymer characterization}

The number average molar mass $\left(\mathrm{M}_{\mathrm{n}}\right)$, mass average molar mass $\left(\mathrm{M}_{\mathrm{w}}\right)$, and polydispersity index (PDI) of PCL were characterized by gel permeation chromatography (GPC). Briefly, scaffolds were dissolved in tetrahydrofuran (THF) (Sigma-Aldrich) to obtain a PCL solution of $1 \mu \mathrm{g} \mu \mathrm{l}^{-1}$. Chromatographic analysis was carried out on a GPC system (SECcurity, GPC System PSS 1260 Infinity, Agilent Technologies) using $10 \mu \mathrm{l}$ of PCL solution, at $37^{\circ} \mathrm{C}$ with a flow rate of $0.3 \mathrm{ml} \mathrm{min}{ }^{-1}$. Measurement calibration was performed using a polystyrene standard (PSS polymer standards, Mainz, Germany).

\subsection{Isolation of human adipose-derived mesenchymal stromal cells (AdMSC)}

Fat tissue was obtained from a healthy donor after written informed consent from the patient. The study was approved by the institutional review board and carried out following the Declaration of Helsinki principles. Isolation of AdMSC from fat tissue was performed as reported by Schneider et al [31]. Briefly, fat tissue was minced into small pieces using a scalpel and placed into $50 \mathrm{ml}$ Falcon tubes (Eppendorf, Germany). Next, the tissue was centrifuged at $430 \mathrm{~g}$ to separate the stromal fraction. After centrifugation, fat tissue was digested with $1.45 \%$ collagenase solution (Merck Millipore, USA) for $30 \mathrm{~min}$ at $37^{\circ} \mathrm{C}$ and centrifuged at $600 \mathrm{~g}$ to obtain a cell pellet. Cells were cultured in $175 \mathrm{~cm}^{2}$ cell culture flasks (Eppendorf, Germany) in DMEM medium supplemented with $10 \%$ fetal calf serum (FCS) and $1 \%$ penicillin/ streptomycin $(\mathrm{P} / \mathrm{S})$. Cultures were maintained at $37{ }^{\circ} \mathrm{C}$ and $5 \% \mathrm{CO}_{2}$ in a humidified incubator. Medium was changed twice a week and cells were passaged at $80 \%$ confluency.

\subsection{Culture for migration assay}

The migration assay was performed on 12-well plates (Eppendorf, Germany) using a custom designed 3D printed flexible clamp (supplementary figure 1(a) available online at stacks.iop.org/BMM/ $14 / 065002 /$ mmedia) to hold the scaffolds (nominally $3.175 \mathrm{~mm} \times 4.7625 \mathrm{~mm} \times 19.5 \mathrm{~mm}$ ) in place. The scaffold holders were sterilized with the same method described in section 2.8. Briefly, $5 \times 10^{4}$ (passage 3) AdMSCs were seeded onto each well and left in a humidified incubator at $37^{\circ} \mathrm{C}$ and $5 \% \mathrm{CO}_{2}$ for two hours to allow for cell attachment. Then, aseptically and gently, the scaffolds in their holders were positioned in the wells (supplementary figure 1(b)). Culture was maintained for 10, 20, and 30 days with DMEM supplemented with $10 \%$ FCS and 1\% $\mathrm{P} / \mathrm{S}$ in a humidified incubator at $37^{\circ} \mathrm{C}$ and $5 \% \mathrm{CO}_{2}$.

\subsection{Fluorescent staining of scaffold culture and migration assay}

At days 10, 20, and 30, scaffolds were harvested and stained with Hoechst (Sigma-Aldrich) and Phalloidin (Sigma-Aldrich) for visualization of cells under confocal laser scanning microscopy (Olympus Fluoview FV10i). Briefly, scaffolds were transferred to a new well plate and washed twice with $0.5 \mathrm{mM} \mathrm{Mg}^{2+}, 0.9 \mathrm{mM}$ $\mathrm{Ca}^{2+} 1 \times$ phosphate buffered saline (PBS) solution. Next, cells were fixed with $4 \%$ formaldehyde for $30 \mathrm{~min}$ at room temperature. After fixation, the scaffolds were washed with plain $1 \times$ PBS and permeabilized with a $0.2 \%$ Triton X-100 in PBS solution for $5 \mathrm{~min}$. Samples were washed twice with $1 \times$ PBS then transferred into a $0.5 \%$ bovine serum albumin (BSA) in PBS solution to incubate for $10 \mathrm{~min}$. A fluorescent staining solution containing a ratio of Hoechst 1:2000 and Phalloidin 1:1000 in 0.5\% BSA/PBS was prepared. The scaffolds were incubated for $45 \mathrm{~min}$ in this solution, covered from light. After incubation in the staining solution, the scaffolds were again rinsed with $1 \times \mathrm{PBS}$ and stored in $1 \times \mathrm{PBS}$ at $4{ }^{\circ} \mathrm{C}$ until they could be viewed with confocal microscopy. Extent of cell migration along the length of the scaffolds was measured using the Olympus Fluoview FV10i microscopy proprietary software.

\subsection{Statistical analysis}

For the comparison between FE compression simulation and compression test experiments, a linear regression analysis between the effective Young's moduli from simulation and experiment was used and the respective $\mathrm{R}^{2}$-value was calculated. Similarly, linear regression of the simulated Young's modulus dependence on the scaffold porosity was calculated.

The significance of the differences in cell migration distance were assessed using Tukey Honest Significant Differences. GPC data was subjected to twoway analysis of variance and Tucker's post-hoc test using SPSS Statistics (Version 25). Significance level was set at $p<0.05$.

\section{Results}

\subsection{Scaffold fabrication}

In this study, 3D printed scaffolds were generated through the establishment of the design-to-manufacturing workflow. Firstly, scaffold models generated from our customized CAD tool were meshed into finely then coarsely resolved meshes (figure 2). 

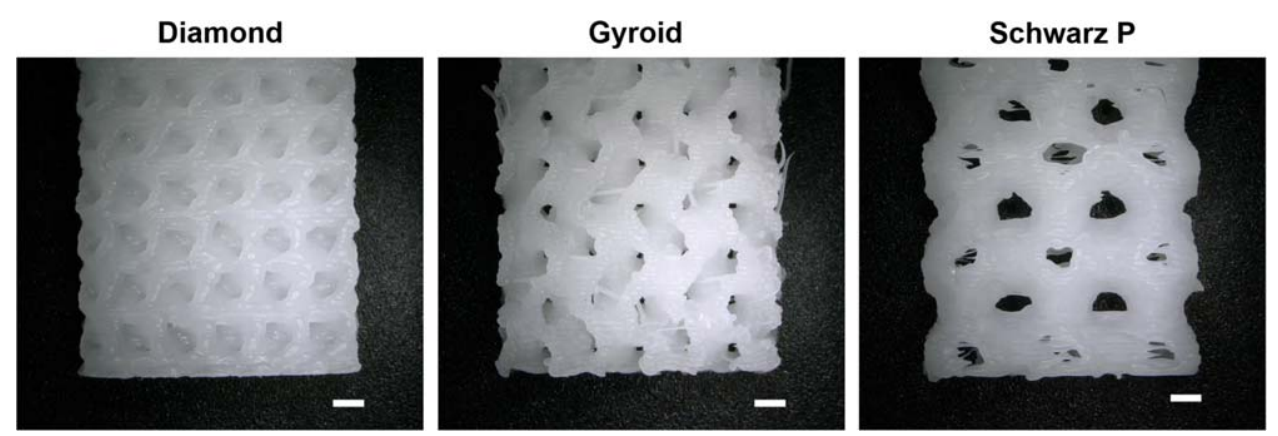

Figure 3. Light microscopy images of the printed scaffolds. Scale bar $=1 \mathrm{~mm}$.

In addition, meshes with finely resolved triangulations were generated from the 3D reconstructed models of printed scaffolds obtained from $\mu \mathrm{CT}$ scan data (figure 2). These scaffold models with finely resolved meshes were used for downstream FE analysis, while the coarsely resolved meshes were used as input for manufacturing of scaffolds with the GESIM BioScaffolder. Light microscopy images of the basic geometries as printed in PCL are shown in figure 3.

In terms of material properties, overall, no significant changes were seen in terms of $M_{w}, M_{n}$ and PDI of PCL when subjected to over $24 \mathrm{~h}$ of pre-heating in the extrusion chamber at $100{ }^{\circ} \mathrm{C}$. Similarly, no significant changes in the PCL's $\mathrm{M}_{\mathrm{w}}, \mathrm{M}_{\mathrm{n}}$ and PDI when exposed to post-treatments with $5 \mathrm{M} \mathrm{NaOH}$ and/or $70 \% \mathrm{EtOH}$. In contrast, a slight decrease in $\mathrm{M}_{\mathrm{n}}$ and $\mathrm{M}_{\mathrm{w}}$ of PCL was observed when scaffolds were subjected to $5 \mathrm{M} \mathrm{NaOH}+70 \% \mathrm{EtOH}+\mathrm{UV}$ post-treatments, while PDI remain unchanged (figure 4).

\subsection{Compression testing and simulation}

In order to assess how well the predicted mechanical competencies were reached in reality, the mechanical properties of the manufactured scaffolds were determined in a non-destructive simulation, then, the relationship between the measured mechanical properties and the simulated properties were compared using a linear regression analysis. The FE analysis shows that the effective Young's modulus of a given architecture, here, Gyroid (using finely resolved meshes of CAD models - figure 2), is dependent on the scaffold porosity, as depicted in figure 5(a).

Figure 5(b) shows a linear regression value of $R^{2}=0.62$ between the experimentally measured and the simulated (using $3 \mathrm{D}$ reconstructed models of printed scaffolds as input) Young's moduli of the scaffolds. The simulated Young's moduli of the original finelyresolved CAD scaffolds are shown as colored lines in the same figure. In figure 5(c), we see the deformed configuration of two representative samples (with a 10-fold exaggerated displacement), as well as the local strain magnitude, in order to illustrate the location of stress concentrations.
A complete list of simulated results using meshes with finely resolved triangulations (figure 2-CAD models) and meshes generated from 3D reconstructed models of printed scaffolds (figure 2-printed models) can be found in supplementary table 1 .

\subsection{MicroCT characterization}

In table 2 , it is notable that the measured porosity of the Gyroid scaffolds with $75 \%$ nominal porosity is nearly the same as the measured porosity of the Gyroid scaffolds with $60 \%$ nominal porosity. Among all the scaffold geometries, Schwarz P scaffolds have the largest mean pore size compared to scaffolds of Gyroid or Diamond architectures.

Analysis of the pore size distribution across all scaffolds as illustrated in figure 6 shows that scaffolds with Diamond geometry have a relatively larger fraction of pore sizes under $800 \mu \mathrm{m}$ compared to both Gyroid and Schwarz P scaffolds. Scaffolds of Gyroid geometry with $60 \%$ or $75 \%$ nominal porosity showed similar pore size distribution, with a tight peak between 700 and $1000 \mu \mathrm{m}$. On the other hand, scaffolds of Schwarz P geometry showed the broadest distribution of pore sizes, with a large fraction of pores over $1000 \mu \mathrm{m}$.

\subsection{Cell migration assay}

Finally, we assessed the influence of the different architectures on cell migration. Figure 7(a) shows that AdMSCs were able to migrate along the length of all scaffold geometries over the $30 \mathrm{~d}$ culture period. On day 10 , no significant difference was observed in terms of the AdMSC's migration distance in relation to the scaffolds' geometry or surface properties (with or without $\mathrm{CaP}$ coating). On day 20, AdMSCs showed a similar migration rate on all PCL scaffolds coated with CaP. The uncoated PCL scaffolds, however, showed greater (though nonsignificant) migration distance along the scaffolds with Diamond and Gyroid geometries compared to that of Schwarz P scaffolds. On day 30, Schwarz P scaffolds with or without $\mathrm{CaP}$ coating showed similar AdMSC migration distance (figure 7(b)). The CaP coating on scaffolds with Diamond or Gyroid geometry significantly increased the distance of AdMSC migration versus uncoated scaffolds. Notably, regardless of CaP coating, AdMSCs 


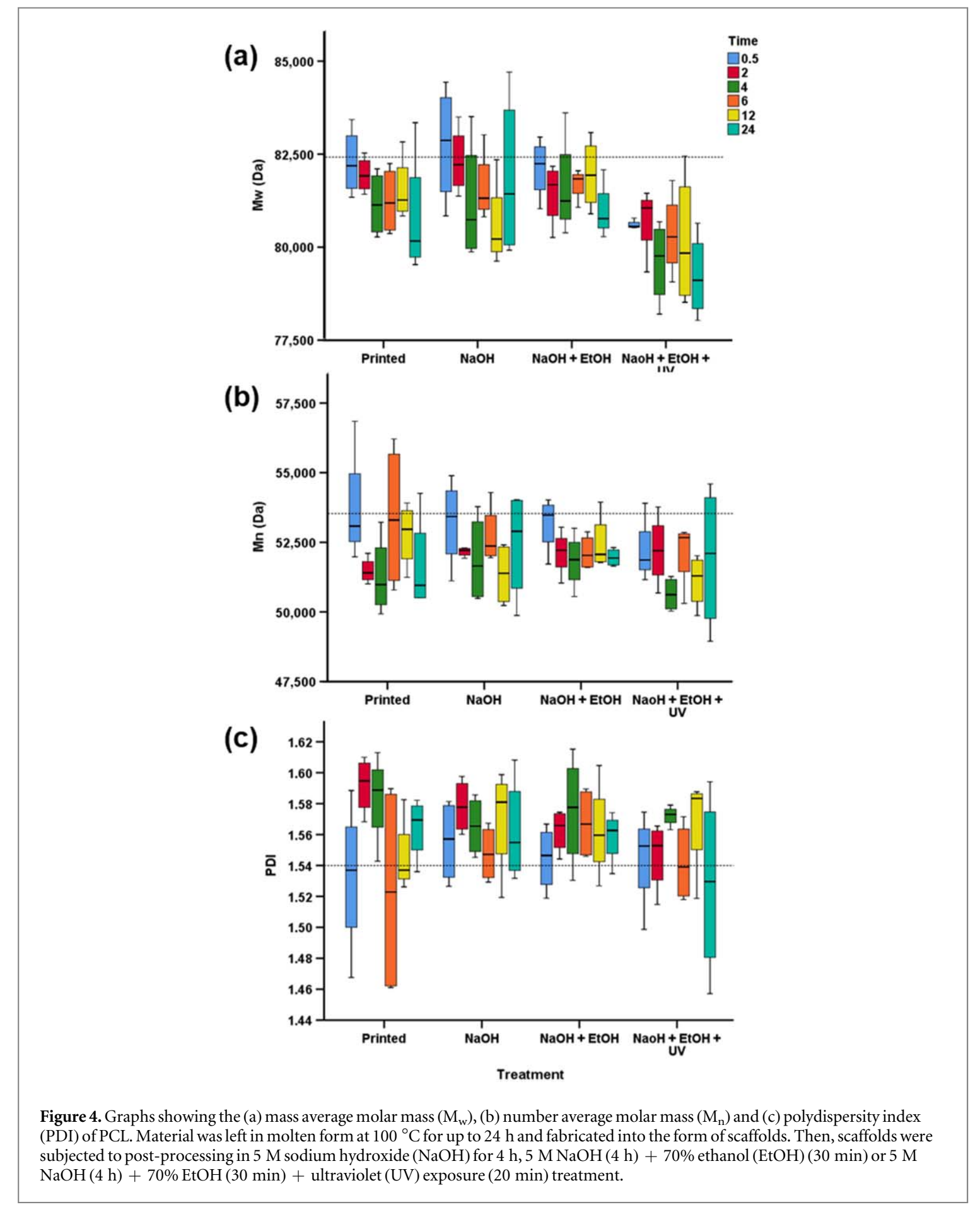

migrated significantly further on scaffolds of Diamond or Gyroid geometry compared to that of scaffolds with Schwarz P geometry (figure 7(b)). Morphological evaluation (figure 7(c)) showed that AdMSCs migrated into the scaffolds of Diamond, Gyroid and Schwarz P geometries and occupied the void spaces within the scaffolds.

\section{Discussion}

\subsection{Scaffold design and manufacturing processes}

In this study, scaffolds were created from unit cells comprised of Gyroid, Diamond or Schwarz P architectures. The dimension of each unit cell was $3.175 \mathrm{~mm} \times 3.175 \mathrm{~mm} \times 3.175 \mathrm{~mm}$. By varying the wall thickness (determined by the value of $\alpha$, as mentioned in section 2.1), we produced scaffolds models of $60 \%$ or $75 \%$ nominal porosity with finely resolved and complex geometries. Using available (proprietary commercial or open source) mesh generation software (e.g. n-Topology, Rhino3d with Grasshopper), we did not succeed in generating suitable meshes usable for FE analysis due to topological mesh defects, e.g. nonmanifold edges or holes. The design workflow implemented in this study is thus comprised of several steps using custom-made MATLAB and $\mathrm{C}++$ programs 


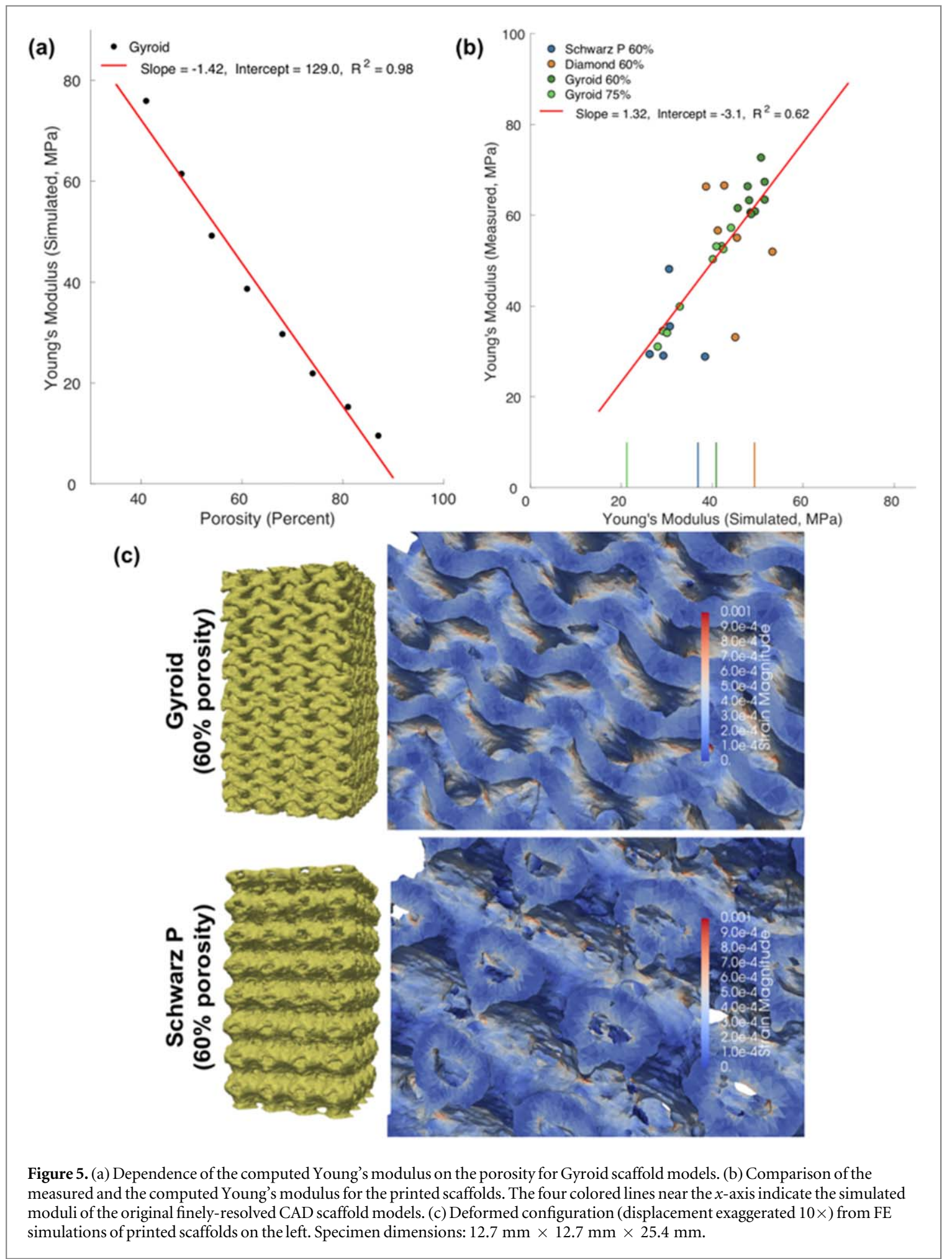

Table 2. Geometric data acquired by $\mu \mathrm{CT}$ scanning of the printed scaffolds.

\begin{tabular}{lcc}
\hline Geometry and nominal porosity & Pore size, $\mu \mathrm{m}$ & Porosity, \% \\
\hline Diamond, 60\% Porosity & $806 \pm 21$ & $65 \pm 2$ \\
Gyroid, 60\% Porosity & $803 \pm 35$ & $57 \pm 1$ \\
Gyroid, 75\% Porosity & $863 \pm 19$ & $63 \pm 4$ \\
Schwarz P, 60\% Porosity & $1356 \pm 41$ & $65 \pm 2$ \\
\hline
\end{tabular}

enabling the generation of meshes with finely resolved triangulations that can be used in FE analysis. Furthermore, the geometric complexity and the size of the scaffolds exceeded the capacity of the printer's slicer software, necessitating a drastic reduction of the polygon count of the input.STL files (figure 2-CAD models with coarsely resolved triangulations), using the established workflow for generation of printable scaffold models. 


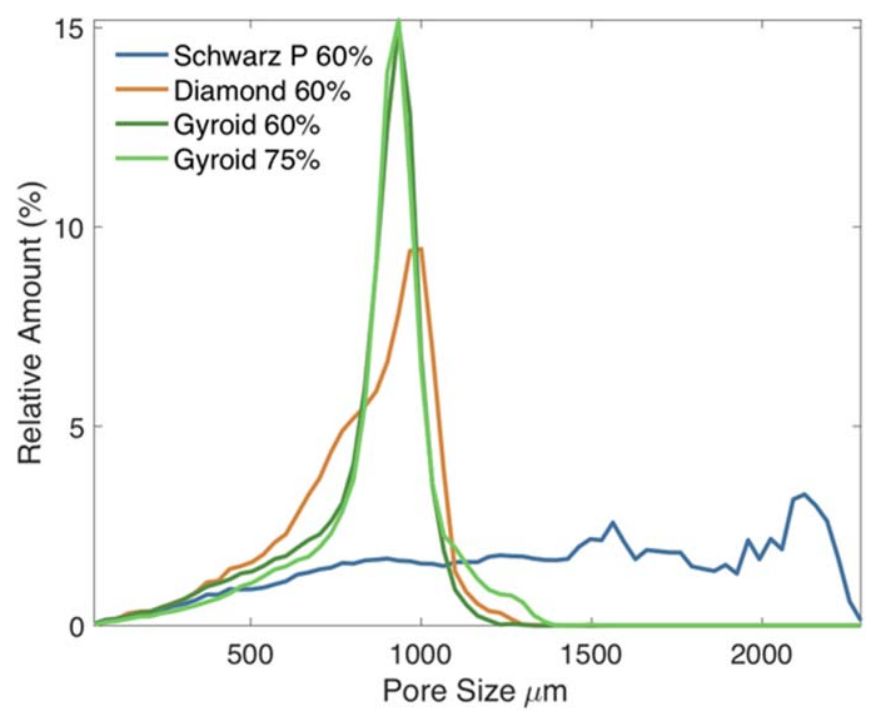

Figure 6. Distribution of pore sizes for the scaffolds with Schwarz P, Diamond and Gyroid geometries with either $60 \%$ or $75 \%$ nominal porosity.

Upon generation of printable models, scaffolds were additively manufactured following the print parameters listed in table 1 . Due to the system configuration of the GESIM BioScaffolder impeding the software-to-machine communication of G-code files larger than $15 \mathrm{MB}$, the Diamond scaffolds were printed with increased distance between strands $(0.15 \mathrm{~mm})$ to reduce the $\mathrm{G}$-code command lines, and hence the file size, while not compromising the print quality.

Using the pneumatic feeder system of the GESIM BioScaffolder, all scaffolds were printed at $660 \mathrm{kPa}$, approaching the technical upper safety threshold recommended by the manufacturer. Nonetheless, the total print time for a scaffold measuring 12.7 $(\mathrm{w}) \times 12.7$ (l) $\times 25.4$ (h) $\mathrm{mm}$ was approximately eight hours, limiting the translational potential of the scaffolds for real-world application. To circumvent this, it may be necessary to investigate the use of a screw-based extrusion feeder system which has could potentially increase the extrusion rate of material of high viscosity (i.e. similar to molten PCL) leading to significantly shortened print time, while maintaining the flexibility for biomaterials.

Finally, the correspondence between the printed and designed scaffolds, in particular with respect to their porosity, was not always adequate (see supplementary table 1 and figure 2) due to deficiencies of the printing technology or environment. Specifically, the $75 \%$ porosity Gyroid scaffold models ended up with a printed porosity of only $63 \%$, which is also reflected in the resulting effective Young's moduli. Hence, there is a need for a tighter quality control (QC) system throughout the AM processes, including the print environment. Investigating our manufacturing process, we found that there is a significant wear and tear on the extrusion nozzles (Stainless Steel SUS 303), which require frequent replacement (supplementary figure 2) to ensure a consistent polymer melt flow pattern. Using a novel setup of rheological extrusion slit die, Zitzenbacher and Brunner [32] illustrated that tool surface can influence the polymer melt flow, and vice versa, the surface properties of the tool change during the extrusion process. Another potential factor in print consistency could be the ambient temperature. In this study, all scaffolds were printed at room temperature, which fluctuated between $24^{\circ} \mathrm{C}$ and $29^{\circ} \mathrm{C}$ dependent on the season and time of printing. It is widely accepted that ambient temperature and humidity can affect the print quality due to the phenomenon of polymer warping, which occurs during the solidification of polymer melt after extrusion [33]. To circumvent this, it may be necessary to have the $3 \mathrm{D}$ printer enclosed within an ambiently controlled box to allow uniform cooling of the printed scaffold. Such a strategy has been adopted for industrial-scale 3D printers, but has not yet been widely adopted for laboratory/ research-level 3D printing, mainly due to the high development and maintenance cost.

Generally, during the process of melt-extrusion based AM of scaffolds, the PCL was melted at $100{ }^{\circ} \mathrm{C}$ and was kept in its molten form for a prolonged period of time. In our case, PCL pellets were usually left in the material chamber for $30 \mathrm{~min}$ (to allow the PCL to melt fully) prior to the commencement of scaffold production. Subsequently, scaffolds were subjected to posttreatment with $5 \mathrm{M} \mathrm{NaOH}$ to improve the scaffold surface hydrophilicity followed by sterilization with $70 \% \mathrm{EtOH}$ and UV. To ensure the quality of the scaffolds, it is crucial that the PCL bulk properties remain 


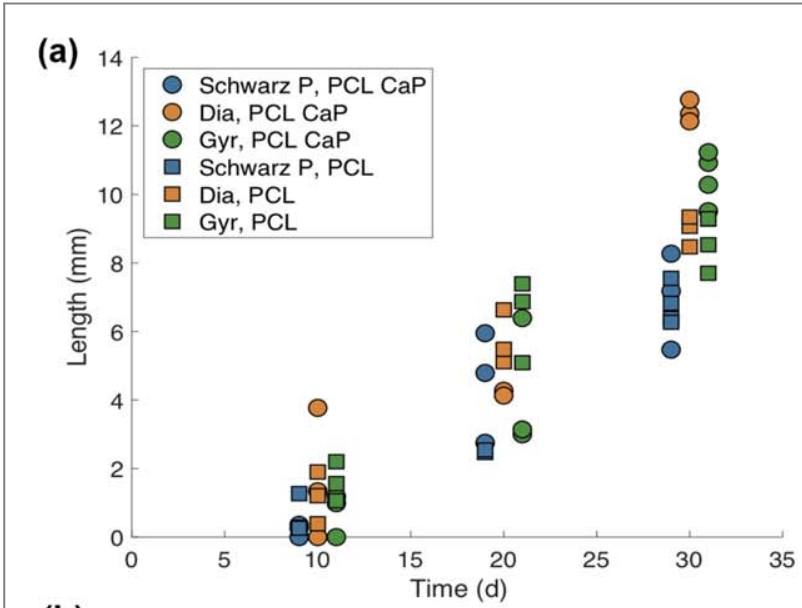

(b)

(d)
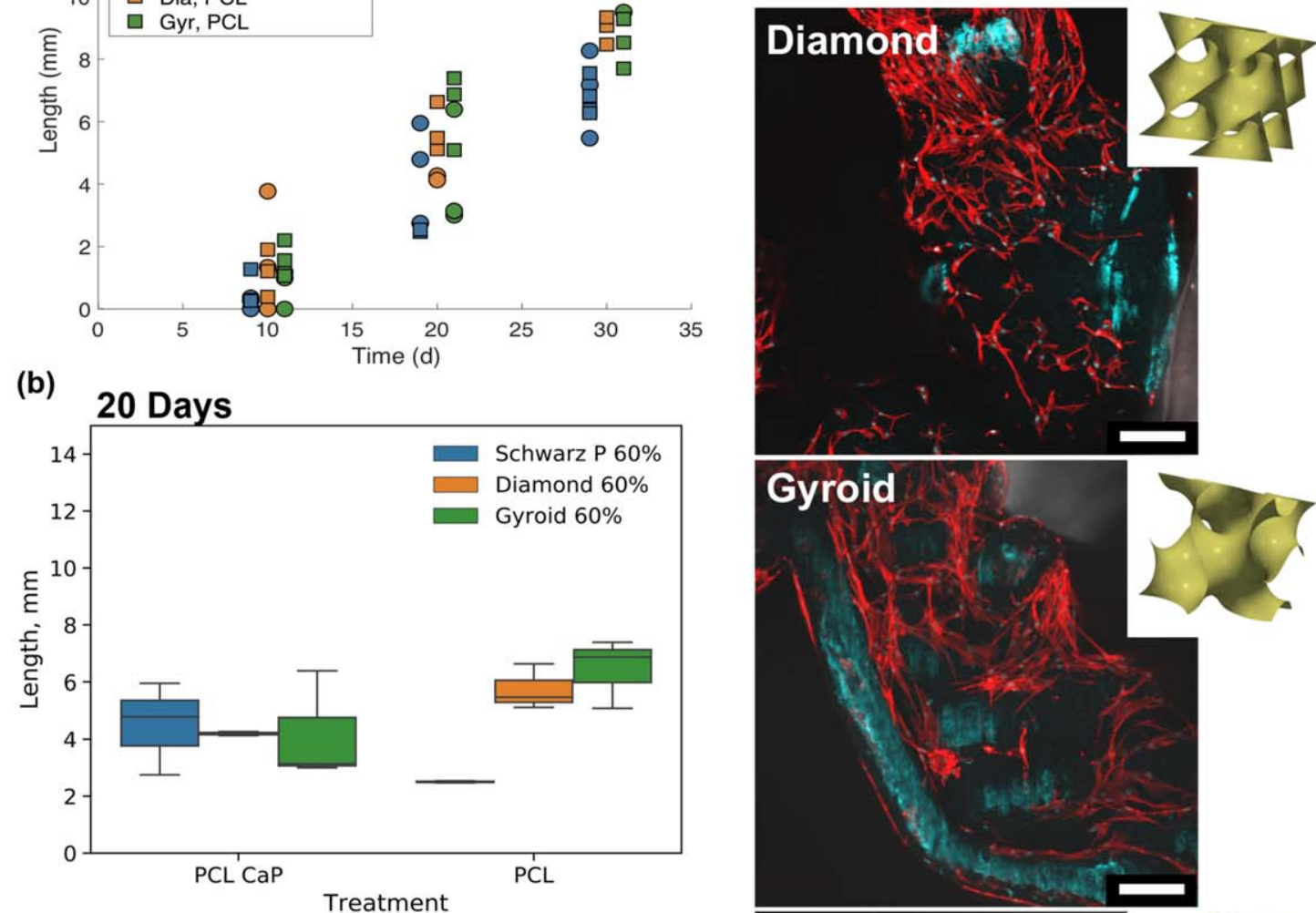

(c) 30 Days
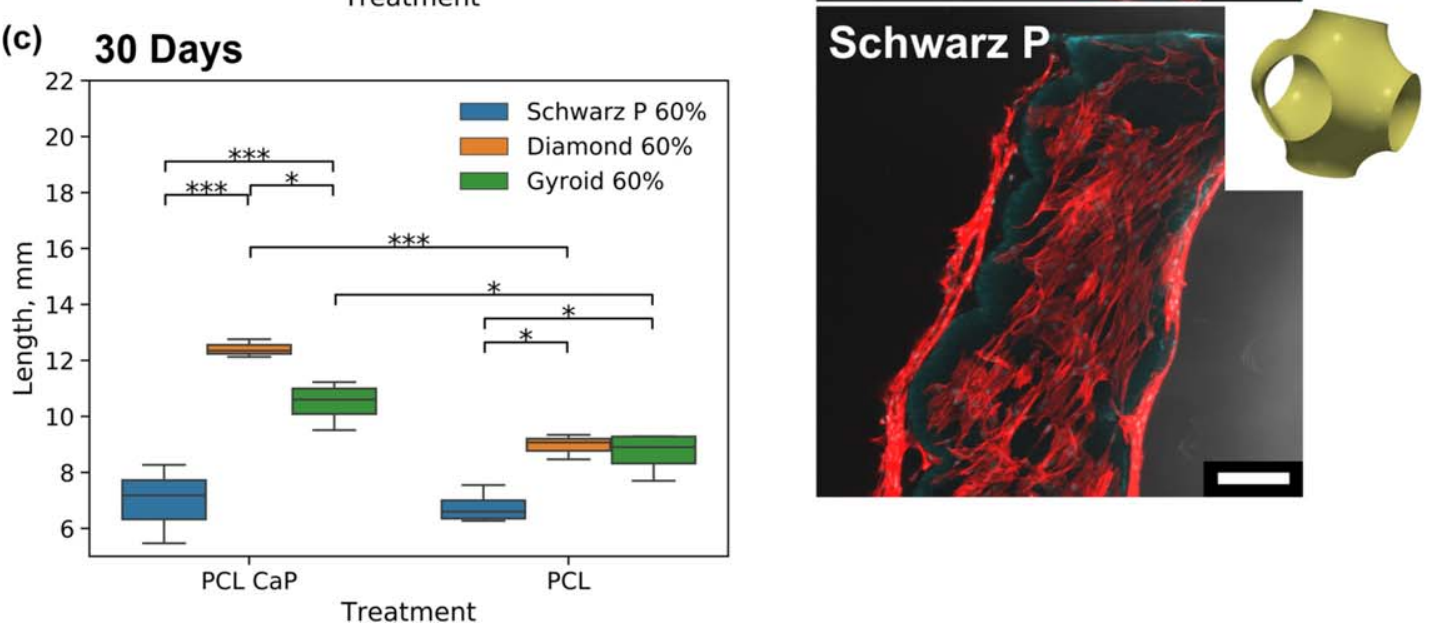

Figure 7. (a) Graph illustrates the individual data points for cell migration along the length of scaffolds with Schwarz P, Diamond (Dia) or Gyroid (Gyr) geometries on days 10, 20, and 30. Cell migration was evaluated on polycaprolactone (PCL) scaffolds, with or without surface calcium phosphate (CaP) coating. $n=3$ for each group. (b)-(c) Box plot for the cell migration distance for PCL and PCL-CaP scaffolds with Schwarz P, Diamond or Gyroid geometries on days (b) 20 and (c) 30 . The * indicate $p$-values for differences using Tukey Honest Significant Differences, where $p<0.05$ is $\left({ }^{*}\right), p<0.01$ is $\left({ }^{* *}\right)$, and $p<0.001$ is $\left({ }^{* * *}\right)$. We note that no significant differences were found in the $20 \mathrm{~d}$ data; the PCL Schwarz P measurement yielded only two data points. (d) Representative confocal microscopy images of PCL-CaP scaffolds cultured with adipose-derived mesenchymal stromal cells (AdMSCs) for $30 \mathrm{~d}$. Red = actin filaments,

blue autofluorescence $=$ scaffold. Scale bar $=200 \mu \mathrm{m}$.

unaltered throughout the process [34]. GPC analysis showed that PCL was resistant to thermal degradation up to $24 \mathrm{~h}$, with no significant change in the $\mathrm{M}_{\mathrm{w}}, \mathrm{M}_{\mathrm{n}}$, and PDI. This is expected, as thermal degradation of PCL typically starts at $390{ }^{\circ} \mathrm{C}$ in nitrogen and at $250{ }^{\circ} \mathrm{C}$ in oxygen [35]. Routine post-treatment of scaffolds with $5 \mathrm{M} \mathrm{NaOH}$ (4 h) and/or 70\% EtOH (30 min) did not affect the PCL's $\mathrm{M}_{\mathrm{w}}, \mathrm{M}_{\mathrm{n}}$, and PDI. However, the subsequent exposure to UV (20 min), although not significant, slightly decreases the $\mathrm{M}_{\mathrm{n}}$ and $\mathrm{M}_{\mathrm{w}}$ of PCL. The phenomenon of photodegradation of PCL upon exposure to UV radiation has been previously reported $[36,37]$. Long term exposure of PCL to UV radiation ( $>1$ week) caused photodegradation of PCL by a 
bulk erosion mechanism through random scission of polymer chains and formation of new carbonyl groups $(\mathrm{C}=\mathrm{O})$ within the PCL macromolecules $[36,37]$. In this study, the total exposure time of PCL scaffolds to UV was $40 \mathrm{~min}$. Hence, only a negligible effect of photodegradation was observed.

\subsection{Scaffolds' compressive moduli-simulation and experiment}

One goal of this work was to assess the predictive capability of numerical simulations for the mechanical performance of additively manufactured polymer scaffolds. Since effective elastic moduli were to be compared, a linearized elasticity model was deemed suitable for the simulations. We note that PCL (here with a measured Young's modulus of $222.8 \pm 6.0 \mathrm{MPa}$ $(N=4))$ is still much less stiff than both cancellous and cortical bone (collectively showing a range in Young's modulus of ca. 0.1-20 GPa) [38]. Therefore, regarding purely the mechanical performance of a porous PCL scaffold architecture for bone tissue engineering, the goal is to maximize its stiffness.

We notice a clear correlation when using 3D reconstructed models of printed scaffolds as input to the numerical simulation of compression tests with the experimentally measured modulus (figure 5(b)). There was a large discrepancy between numerical simulation of the idealized geometries, i.e. CAD generated scaffolds with finely resolved meshes versus the printed scaffolds (figure 2), as can be seen in supplementary table 1 . This is also reflected by the large discrepancy between the geometries of the designed and printed scaffolds (table 2). This should be noted when assessments of the mechanical performance of scaffolds are based solely on computations using idealized TPMS geometries with no manufacturing imperfections, as was investigated in [9]. Thus, in the future, it will be necessary to investigate the discrepancy between printed geometries (both random and systematic) and the original designs, for example by means of uncertainty quantification. This way, potential print artifacts, i.e. stratified surfaces due to the layer-by-layer manufacturing of constructs common to melt-extrusion 3D printing techniques, can be taken into consideration during the computer-aided design and engineering process.

When PCL is fabricated into the form of scaffolds, the Young's modulus will be compromised. Our study indicated that among the tested TPMS geometries, scaffolds (porosity $=60 \%$ ) with Gyroid geometry exhibited the highest moduli (>60 MPa, see supplementary table 1) compared to other geometries, i.e. Diamond or Schwarz P. When compared to PCL scaffolds of raster-angle geometry with a similar porosity [39], TPMS geometries show the potential to improve PCL scaffold moduli. In Bartnikowski et al [39], despite the varying raster-angle designs, PCL scaffolds'
Young's moduli did not exceed $20 \mathrm{MPa}$, whereas in this study, all scaffolds showed Young's modulus greater than $20 \mathrm{MPa}$ (see supplementary table 1). Nonetheless, the moduli of the printed constructs are still far below the elastic modulus of bone. To improve the scaffolds' strength, composite biomaterials would be an option [40]. This presents a potential avenue to explore in the future, with the consideration that manufacture and simulation of composite materials is more complicated.

In figure 5(a), the computed dependence of the mechanical modulus on the porosity is shown. Here, of course, designed geometries were used for the simulation, since it was not possible to print scaffolds with very high porosities with our current $3 \mathrm{D}$ printer settings. From the data it is clear that the relationship is not entirely linear. Nevertheless in the (most biologically relevant) region of porosities of $60-80 \%$, an approximation by a linear relation, which was also the approach taken in [41], seems reasonable.

PCL scaffolds to be implanted would likely be subjected to post-processing to improve surface properties, e.g. hydrophilicity, for an improved biological response. Therefore, testing on thusly treated scaffolds would be interesting for the sake of completeness. However, in this study, we do not expect a surface treatment with $\mathrm{NaOH}$ etching and/or CaP-coating to significantly affect the mechanical properties-rather a change in degradation profile [42] and biological mechanisms [11] might be observable.

\subsection{Cell migration assay and relation to scaffold geometries}

In the short-term cultures $(10 \mathrm{~d})$, there was minimal distinction between the various geometries (figure 7(a)). However, by $30 \mathrm{~d}$, it was clearly shown that AdMSCs were able to migrate furthest on scaffolds with Diamond geometry, followed by Gyroid and Schwarz P geometries (figure $7(\mathrm{c})$ ). Table 2 and figure 6 show that, for a given porosity, the Gyroid and Diamond geometries had a similar average pore size, but tighter curvatures (smaller pore sizes) are more prevalent in the Diamond structures compared to the Gyroid, which has a relatively sharp peak at around $800 \mu \mathrm{m}$. This could possibly partially explain the faster migration on the Diamond versus Gyroid scaffolds. Recently, Werner et al demonstrated that increased curvature of surface promoted human bone marrow stromal cell migration through F-actin-myosin contractility [43]. To further elucidate this, it may be necessary to perform an indepth analysis on the F-actin-myosin mechanism of AdMSCs when cultured on scaffolds with different TPMS geometries. The difference in curvature is not surprising (applying multiplication theorems for trigonometric functions) since the implicit functions approximating Diamond structures include products of three sin-cos terms, as opposed to two for Gyroid. 
The CaP coating does seems to provide an advantage for cell migration on scaffolds with Diamond and Gyroid geometries, but not Schwarz P scaffolds. The pores of scaffolds with Schwarz $\mathrm{P}$ architecture are relatively large compared to scaffolds with Gyroid or Diamond architecture (figure 6 and table 2), thus cell migration is impeded even with the benefit of $\mathrm{CaP}$ coating. This is in line with the correspondence between pore sizes and cell migration found in [44-46]. Presently, the cellular behavior investigated in this study is limited to migration of AdMSCs. Beyond the scope of this study, it would be of interest to further explore the influence of TPMS geometry on cellular behaviors, such as, but not limited to, cellular differentiation, metabolic states and kinetics of extracellular matrix secretion of different cell sources. This way, correlations of cellular behaviors with variations in TPMS structure could be cataloged, enabling data-driven design and engineering of scaffolds, i.e. scaffolds with varying geometries and porosity at different length scales [47], to better support bone regeneration.

\section{Conclusion}

The main goal of this study is to establish and validate the computer aided design and engineering (CADE) workflow for the generation and simulation of mechanical properties of scaffolds with TPMS geometry. As we show in the present study, substantial effort is required for the AM of scaffolds that are faithful to the finely resolved designed structures used in initial FE analysis. The printed geometries still do show a large (both random and systematic) deviation from the designs. We expect this deviation to decrease with further advances in printing technology. Nonetheless, numerical simulation is still a reasonable intermediate design step to save production time and reduce destructive testing. In particular, the numerically computed effective Young's modulus provides a good indicator of the mechanical performance of a manufactured scaffold.

The second goal of this study focuses on evaluating the possibility of scaffolds' macro-geometry in regulating AdMSC migration. We find that scaffold macro-geometries, e.g. TPMS geometry with pore size $>800 \mu \mathrm{m}$, do have an effect on the AdMSC migration rate. Hence, it may be advantageous to select geometries not only with regards to their mechanical performance, but also to take into account the finer details of the surface geometry when designing scaffolds intended for bone tissue engineering. Overall, we consider this study to be a stepping-stone to a design process that considers not only mechanical properties but also cellular behavior.

\section{Acknowledgments}

We would like to thank Prof Ulrike Protzer of the Department of Virology, Technical University of Munich for the use of the confocal laser scanning microscope. We would also like to thank BellaSeno $\mathrm{GmbH}$ for the use of the $3 \mathrm{D}$ printer. PWD acknowledges partial support by the German Scholars Organization/Carl-Zeiss-Stiftung in the form of the 'Wissenschaftler-Rückkehrprogramm'.

\section{Statement of significance}

To our knowledge, (1) this is the only study that compares FE analysis of not only idealized TPMS structures for bone tissue engineering, but also reconstructions of actual printed PCL samples with experimental mechanical testing. (2) In addition, we see a significant difference in cell migration on a selection of TPMS structures, an interesting result warranting further investigation.

\section{ORCID iDs}

Patrina S P Poh (10 https:// orcid.org/0000-00019104-0910

\section{References}

[1] Zein I, Hutmacher D W, Tan K C and Teoh S H 2002 Fused deposition modeling of novel scaffold architectures for tissue engineering applications Biomaterials 23 1169-85

[2] Giannitelli S M, Accoto D, Trombetta M and Rainer A 2014 Current trends in the design of scaffolds for computer-aided tissue engineering Acta Biomater. 10 580-94

[3] Roohani-Esfahani S I, Newman P and Zreiqat H 2016 Design and fabrication of $3 \mathrm{D}$ printed scaffolds with a mechanical strength comparable to cortical bone to repair large bone defects Sci. Rep. 619468

[4] Gleadall A, Visscher D, Yang J, Thomas D and Segal J 2018 Review of additive manufactured tissue engineering scaffolds: relationship between geometry and performance Burns Trauma 619

[5] Reichert J C, Epari D R, Wullschleger M E, Berner A, Saifzadeh S, Noth U, Dickinson I C, Schuetz M A and Hutmacher D W 2012 [Bone tissue engineering. Reconstruction of critical sized segmental bone defects in the ovine tibia] Orthopade 41 280-7

[6] Henkel J, Woodruff M A, Epari D R, Steck R, Glatt V, Dickinson I C, Choong P F, Schuetz M A and Hutmacher D W 2013 Bone regeneration based on tissue engineering conceptions - A 21st century perspective Bone Res. 1216-48

[7] Karageorgiou V and Kaplan D 2005 Porosity of 3D biomaterial scaffolds and osteogenesis Biomaterials 26 5474-91

[8] Rajagopalan S and Robb R A 2006 Schwarz meets Schwann: design and fabrication of biomorphic and durataxic tissue engineering scaffolds Med. Image Anal. 10 693-712

[9] Kapfer S C, Hyde S T, Mecke K, Arns CH and Schroder-Turk G E 2011 Minimal surface scaffold designs for tissue engineering Biomaterials 32 6875-82

[10] Woodruff M A and Hutmacher D W 2010 The return of a forgotten polymer-Polycaprolactone in the 21st century Prog. Polym. Sci. 35 1217-56

[11] Poh P S P, Hutmacher D W, Holzapfel B M, Solanki A K, Stevens M M and Woodruff M A 2016 In vitro and in vivo bone formation potential of surface calcium phosphate-coated polycaprolactone and polycaprolactone/bioactive glass composite scaffolds Acta Biomater. 30 319-33 
[12] Olivares A L, Marsal E, Planell J A and Lacroix D 2009 Finite element study of scaffold architecture design and culture conditions for tissue engineering Biomaterials 30 6142-9

[13] Yoo D J 2011 Porous scaffold design using the distance field and triply periodic minimal surface models Biomaterials 32 7741-54

[14] Shin J, Kim S, Jeong D, Lee H G, Lee D, Lim JY and Kim J 2012 Finite element analysis of schwarz p surface pore geometries for tissue-engineered scaffolds Math. Probl. Eng. 2012 1-13

[15] Kadkhodapour J, Montazerian H and Raeisi S 2014 Investigating internal architecture effect in plastic deformation and failure for TPMS-based scaffolds using simulation methods and experimental procedure Mater. Sci. Eng. C 43 587-97

[16] Melchels F P, Bertoldi K, Gabbrielli R, Velders A H, Feijen J and Grijpma D W 2010 Mathematically defined tissue engineering scaffold architectures prepared by stereolithography Biomaterials 31 6909-16

[17] Ronca A, Ambrosio L and Grijpma D W 2013 Preparation of designed poly(D,L-lactide)/nanosized hydroxyapatite composite structures by stereolithography Acta Biomater. 9 5989-96

[18] Cipitria A, Lange C, Schell H, Wagermaier W, Reichert J C, Hutmacher D W, Fratzl P and Duda G N 2012 Porous scaffold architecture guides tissue formation J. Bone Miner. Res. 27 1275-88

[19] Cipitria A, Reichert J C, Epari D R, Saifzadeh S, Berner A, Schell H, Mehta M, Schuetz M A, Duda G N and Hutmacher D W 2013 Polycaprolactone scaffold and reduced rhBMP-7 dose for the regeneration of critical-sized defects in sheep tibiae Biomaterials 34 9960-8

[20] Paris Met al 2017 Scaffold curvature-mediated novel biomineralization process originates a continuous soft tissueto-bone interface Acta Biomater. 60 64-80

[21] Pobloth A M et al 2018 Mechanobiologically optimized 3D titanium-mesh scaffolds enhance bone regeneration in critical segmental defects in sheep Sci. Transl. Med. 10 eaam 8828

[22] Petersen A et al 2018 A biomaterial with a channel-like pore architecture induces endochondral healing of bone defects Nat. Commun. 94430

[23] Brakke K 2018 Triply Periodic Minimal Surfaces (http://facstaff. susqu.edu/brakke/evolver/examples/periodic/periodic.html)

[24] Laurent Rineau M Y 2018 3D Surface Mesh Generation CGAL User and Reference Manual ed C E Board

[25] Cignoni P, Callieri M, Corsini M, Dellepiane M, Ganovelli F and Ranzuglia G 2008 MeshLab: an open-source mesh processing tool ed V Scarano et al Eurographics Italian chapter Conf., The Eurographics Association

[26] ASTM 2015 International, Standard Test Method for Compressive Properties of Rigid Plastics ASTM Internationa

[27] Si H 2015 TetGen, a Delaunay-Based Quality Tetrahedral Mesh Generator ACM Trans. Math. Softw. 41 1-36

[28] Ho S T and Hutmacher D W 2006 A comparison of micro CT with other techniques used in the characterization of scaffolds Biomaterials 27 1362-76

[29] Jones A C, Arns C H, Sheppard A P, Hutmacher D W, Milthorpe B K and Knackstedt M A 2007 Assessment of bone ingrowth into porous biomaterials using MICRO-CT Biomaterials 28 2491-504

[30] Vaquette C, Ivanovski S, Hamlet S M and Hutmacher D W, 2013 Effect of culture conditions and calcium phosphate coating on ectopic bone formation Biomaterials 34 5538-51

[31] Schneider S, Unger M, van Griensven M and Balmayor E R 2017 Adipose-derived mesenchymal stem cells from liposuction and resected fat are feasible sources for regenerative medicine Eur. J. Med. Res. 2217

[32] Zitzenbacher G and Brunner E B 2017 Evaluation of the influence of the tool surface on polymer melt flow using a novel rheological extrusion slit die Europe/Africa Conf. Dresden 2017 - Polymer Processing Society PPS (Dresden, Germany: AIP Publishing)

[33] Murphy C R, Kolan K C R, Long M, Li W-J, Leu M C, Semon J A and Day D E 3D printing of a polymer bioactive glass composite for bone repair 276th Annual Int. Solid Freeform Fabrication Symp.-An Additive Manufacturing Conf.

[34] Poh P S P, Hege C, Chhaya M P, Balmayor E R, Foehr P, Burgkart R H, Schantz J-T, Schiller S M, Schilling A F and Hutmacher D W 2017 Evaluation of polycaprolactone - polyD, L-lactide copolymer as biomaterial for breast tissue engineering Polym. Int. 66 77-84

[35] Unger M, Vogel C and Siesler H W 2010 Molecular weight dependence of the thermal degradation of poly(epsiloncaprolactone): a thermogravimetric differential thermal Fourier transform infrared spectroscopy study Appl. Spectrosc. 64 805-9

[36] França D C, Morais D D, Bezerra E B, Araújo E M and Wellen R M R 2018 Photodegradation mechanisms on poly $(\varepsilon-$ caprolactone) (PCL) Mater. Res. 21 e20170837

[37] Yeh C-C, Chen C-N, Li Y-T, Chang C-W, Cheng M-Y and Chang H-I 2018 The effect of polymer molecular weight and $\mathrm{UV}$ radiation on physical properties and bioactivities of PCL films Cell. Polym. 30 261-76

[38] Bose S, Roy M and Bandyopadhyay A 2012 Recent advances in bone tissue engineering scaffolds Trends Biotechnol. 30 546-54

[39] Bartnikowski M, Klein T J, Melchels F P and Woodruff M A 2014 Effects of scaffold architecture on mechanical characteristics and osteoblast response to static and perfusion bioreactor cultures Biotechnol. Bioeng. 111 1440-51

[40] Buragohain M K 2017 Composite Structures: Design, Mechanics, Analysis, Manufacturing, and Testing (Oxford: CRC Press)

[41] Poh P S P, Valainis D, Bhattacharya K, van Griensven M and Dondl P 2019 Optimizing Bone Scaffold Porosity Distributions 99170

[42] Poh P S P, Hutmacher D W, Holzapfel B M, Solanki A K and Woodruff M A 2016 Data for accelerated degradation of calcium phosphate surface-coated polycaprolactone and polycaprolactone/bioactive glass composite scaffolds Data Brief7 923-6

[43] Werner M, Kurniawan N A, Korus G, Bouten C V C and Petersen A 2018 Mesoscale substrate curvature overrules nanoscale contact guidance to direct bone marrow stromal cell migration J. R. Soc. Interface 1511

[44] Frosch K H, Barvencik F, Lohmann C H, Viereck V, Siggelkow H, Breme J, Dresing K and Sturmer K M 2002 Migration, matrix production and lamellar bone formation of human osteoblast-like cells in porous titanium implants Cells Tissues Organs 170 214-27

[45] Murphy C M, Haugh M G and O'Brien F J 2010 The effect of mean pore size on cell attachment, proliferation and migration in collagen-glycosaminoglycan scaffolds for bone tissue engineering Biomaterials 31 461-6

[46] Sobral J M, Caridade S G, Sousa R A, Mano J F and Reis R L 2011 Three-dimensional plotted scaffolds with controlled pore size gradients: effect of scaffold geometry on mechanical performance and cell seeding efficiency Acta Biomater. 7 1009-18

[47] Straughan B 2017 Mathematical Aspects of Multi-Porosity Continua (Cham, Switzerland: Springer) (https://doi.org/ 10.1007/978-3-319-70172-1) 